\title{
Penerapan Metode MOORA pada Sistem Penunjang Keputusan Seleksi Karyawan Magang Keluar Negeri (Studi Kasus: PT Hini Daiki)
}

\author{
Teuku Mufizar ${ }^{1}$, Ade Taopik Hidayatuloh², Nanang Suciyono ${ }^{3}$, Alma Husna Hanifah ${ }^{4}$ \\ ${ }^{1,2,3,4}$ Program Studi Teknik Informatika, STMIK Tasikmalaya
}

*fizargama@gmail.com

\begin{abstract}
Employees as one of the resources in a company have an important role in the success or failure of the company in the competition. Companies that are aware of this will of course always provide training for employees to improve the knowledge and skills of employees. PT Hini Daiki as a company engaged in the export garment sector in Tasikmalaya conducts training in the form of sending apprentices abroad. Problems that occur So far, the determination of prospective overseas internships at this company is not as expected, because the selection is direct without using a decision support system, causing inaccurate assessments and not on target. This study aims to apply the MOORA (Multi Objective Optimization on the basis of Ratio Analysis) method in assisting the selection of employees who will be sent for internships abroad at PT. Hi Daiki. The MOORA method is used in the calculation process that produces output in the form of alternative employees who will be sent for internships abroad. The criteria used in this study include activeness in work, mastery of work, discipline, knowledge, teamwork, personality, mastery of language and health. Based on the results of the research, the MOORA method can be well applied to the decision support system for the selection of interns at PT Hini Daiki.
\end{abstract}

Keywords: interns, decision support systems, MOORA

\begin{abstract}
Abstrak
Karyawan sebagai salah satu sumber daya yang ada di suatu perusahaan memiliki peran penting dalam sukses tidaknya perusahaan tersebut dalam persaingan. Perusahaan yang menyadari itu semua tentunya akan senantiasa memberikan pelatihan bagi karyawan guna meningkatkan pengetahuan serta keterampilan dari karyawan. PT Hini Daiki selaku perusahaan yang bergerak pada bidang garment ekspor di Tasikmalaya melakukan pelatihan dalam bentuk pengiriman karyawan magang ke luar negeri. Permasalahan yang terjadi Selama ini, penentuan calon magang keluar negeri pada perusahaan ini kurang sesuai dengan yang diharapkan, dikarenakan pemilihannya secara langsung tanpa menggunakan sistem pendukung keputusan, menyebabkan penilaian yang kurang akurat serta tidak tepat sasaran. Penelitian ini bertujuan untuk menerapkan metode MOORA (Multi Objective Optimization on the basis of Ratio Analysis) dalam membantu seleksi karyawan yang akan dikirimkan magang ke luar negeri di PT Hini Daiki. Metode MOORA digunakan dalam proses perhitungan yang menghasilkan keluaran berupa alternatif karyawan yang akan dikirimkan untuk magang keluar negeri. Kriteria yang digunakan dalam penelitian ini diantaranya keaktifan dalam bekerja, menguasai pekerjaan, disiplin, pengetahuan, Kerjasama tim, kepribadian, penguasaan Bahasa dan Kesehatan. Berdasarkan hasil penelitian metode MOORA dapat dengan baik di terapkan pada system penunjang keputusan seleksi karyawan magang di PT Hini Daiki.
\end{abstract}

Kata kunci: karyawan magang, sistem penunjang keputusan, MOORA

\section{Pendahuluan}

Karyawan sebagai salah satu sumber daya yang ada di suatu perusahaan memiliki peran penting dalam sukses tidaknya perusahaan tersebut dalam persaingan. Karyawan merupakan ujungtombak perusahaan karena ia melakukan pekerjaan dalam perusahaan untuk mencapai tujuan yang ingin dicapai [1]. Disamping itu juga diperlukan karyawan yang dapat berpikir global, artinya pola kerja yang digunakan haruslah sifatnya luwes dan fleksibel, agar perusahaan terus berkembang dan dapat bertahan dalam menghadapi persaingan yang semakin ketat dan kompetitif. Tentunya itu semua akan bisa didapatkan jika didukung 
oleh kayawan yang berkompeten pada pengetahuan, keterampilan dan sikap yang di sesuaikan dengan bidang pekerjaan yang dibutuhkan.

Salah satu upaya pengelolaan karyawan yang baik adalah dengan memberikan pelatihan bagi karyawan di perusahaan guna meningkatkan pengetahuan serta keterampilan dari karyawan. Pelatihan ini dilakukan untuk meningkatkan keterampilan baik softskill maupun hardskill bagi karyawan yang nantinya dapat diimplementasikan pada perusahaan sehingga mampu meningkatkan produktivitas pada perusahaan[2]. Sadar akan hal itu PT Hini Daiki selaku perusahaan yang bergerak pada bidang garment ekspor di Tasikmalaya melakukan pelatihan dalam bentuk pengiriman karyawan magang ke luar negeri. Dengan dilaksanakanya magang, perusahaan menginginkan karyawannya untuk mengembangkan teknologi dan cara kerja agar menjadi karyawan yang lebih disiplin. Hasil dari magang diharpakan agar karyawan mampu mengembangkan ilmunya setelah kembali ke perusahaan dan menjadi pekerja yang baik selama magang di luar negeri.

Karyawan yang dikirimkan sebagai karyawan magang haruslah seorang yang layak, kompeten dan dapat berkembang sekaligus mampu memberikan citra atau gambaran bagus dari pekerja di Indonesia. Permasalahan yang terjadi Selama ini, penentuan calon magang keluar negeri pada perusahaan ini kurang sesuai dengan yang diharapkan, dikarenakan pemilihannya secara langsung tanpa menggunakan sistem pendukung keputusan, menyebabkan penilaian yang kurang akurat serta tidak tepat sasaran. Proses yang berjalan juga dapat dikatakan belum begitu efektif karena proses mengolah data dilakukan dengan metode konvensional, yang berakibat pada waktu pemrosesan menjadi lebih lama. Oleh karena itu, diperlukan suatu sistem penunjang keputusan dengan menggunakan konsep terkomputerisasi dalam upaya menentukan karyawan yang sesuai dengan kriteria, agar pemilihannya menjadi lebih efektif.

Sistem Penunjang keputusan (SPK) adalah sebuah sistem yang memanfaatkan komputer untuk melakukan perhitungan model serta data dalam memecahkan masalah yang terstruktur, ataupun masalah semi terstruktur dengan memberikan informasi maupun alternatif keputusan terhadap permasalahan tertentu [3]. SPK pada sebuah perusahaan telah banyak diterapkan, seperti pada penerimaan karyawan baru [4], promosi jabatan [5] serta pada bidang lainnya [6].

Multi-Objective Optimization on the basis of Ratio Analysis (MOORA) merupakan salah satu metode dalam sistem penunjang keputusan. Metode MOORA adalah sistem yang bersifat multi objektif dan prosesnya akan mengoptimalkan dua atau lebih attribut yang saling bertentangan secara bersamaan. Metode ini dipakai dalam pemecahan masalah yang memiliki perhitungan matematika yang kompleks. MOORA memiliki tingkat selektifitas yang baik dalam menentukan suatu alternatif sehingga menghasilkan suatu keputusan yang akurat dan tepat sasaran[7].

Penelitian ini bertujuan untuk menerapkan metode MOORA (MultiObjective Optimization on the basis of Ratio Analysis) dalam mebantu seleksi karyawan yang akan dikirimkan magang ke luar negeri di PT. Hini Daiki.

\section{Metode Penelitian \\ 2.1. Metode Penelitian}

Penelitian ini menggunakan metode Penelitian kebijakan yang termasuk salah satu dari jenis penelitian deskriptif. Penelitian deskriptif yaitu suatu metode penelitian yang bertujuan untuk menggambarkan fenomenafenomena yang ada. Fenomena tersebut berupa kondisi yang sedang berlangsung saat ini ataupun kondisi saat lampau. Penelitian ini tidak mengadakan pengubahan pada variabelvariabel bebas, akan tetapi menggambarkan suatu kondisi apa yang apaadanya. Penggambaran kondisi bisa berupa individual atau berupa angka-angka.

\subsection{Sistem Penunjang Keputusan}

Sistem Pendukung Keputusan (SPK) adalah sebuah sistem yang dapat memberikan kemampuan pemecahan masalah maupun kemampuan pengkomunikasian pada masalah dengan kondisi semi terstruktur maupun tak terstruktur.[9] Sistem Pendukung Keputusan 
adalah suatu sistem yang membantu proses pengambilan keputusan untuk memecahkan suatu masalah.

\subsection{Multi Objective Optimization on The Basic of Ratio (MOORA)}

Metode moora telah diterapkan dan mampu memecahkan permasalahan terkait ekonomi, proses manajerial dan bidang konstruksi pada sebuah perusahaan ataupun proyek [8].

Adapun langkah penyelesaian dari metode moora adalah:

1. Menginputkan Nilai Kriteria,

2. Membuat Matriks Keputusan, rumus yang digunakan yaitu sebagai berikut :

$\mathrm{X}=\left[\begin{array}{ccccc}x 11 & \ldots & x l i & \ldots & x \ln \\ : & : & : & : & : \\ x j 1 & \ldots & x j i & \ldots & x j n \\ : & : & : & : & : \\ x m 1 & \ldots & x m i & \ldots & x m n\end{array}\right]$

Keterangan :

$\mathrm{x}_{\mathrm{ij}}=$ respon alternative $\mathrm{j}$ pada attribut $\mathrm{i}$

$|\mathrm{i}=1,2, \ldots .$.

$\mathrm{n}=$ jumlah sasaran atau attribut

$\mathrm{j}=1,2, \ldots$.

$\mathrm{m}=$ jumlah alternatif

3. Matriks Normalisasi, rumus yang digunakan adalah :

$$
\mathrm{X}^{*} \mathrm{ij}=\frac{x i j}{\sqrt{\left[\begin{array}{ll}
\sum_{j}^{m}=1 & x i j^{2}
\end{array}\right]}} \ldots \ldots \ldots \ldots \ldots \ldots
$$

Keterangan :

$\mathrm{Xij}=$ matriks alternatif $\mathrm{j}$ dengan kriteria i

$\mathrm{i}=1,2,3 \ldots \mathrm{n}$, urutan kriteria

$\mathrm{j}=1,2,3 \ldots \mathrm{n}$, urutan alternatif

$\mathrm{X}^{*}{ }_{\mathrm{ij}}=$ Matriks normalisasi alternatif $\mathrm{j}$ dengan kriteria $\mathrm{i}$

4. Menghitung Nilai Optimasi, rumus yang digunakan yaitu :

$$
\mathrm{Yi}=\sum_{j=1}^{g} w j x i j-\sum_{j=g+1}^{n} w j x i j
$$

Keterangan :

$\mathrm{g}=$ jumlah attribut yang akan

dimaksimalkan

(n-g) = jumlah attribut yang akan

diminimalkan

$\mathrm{Wj}=$ bobot terhadap $\mathrm{j}$ yi $=$ nilai penilaian yang telah dinormalisasi dari alternatif ke-I terhadap semua attribut.

5. Perangkingan, yaitu mendapatkan Nilai yi. Nantinya yang dinyatakan sebagai alternatif terbaik adalah yang memilikimemiliki nilai yi terbesar. Dan sebaliknya alternatif terburuk adalah yang nilai yi nya terkecil.

\section{Hasil Penelitian}

Penerapan Metode Multi-Objective Optimization on the basis of Ratio Analysis (MOORA) pada sistem penunjang keputusan di PT.Hini Daiki melalui lima tahap penyelesaian yang telah dipaparkan sebelumnya, sebagai berikut :

\subsection{Menginputkan Nilai Kriteria}

Penentuan kriteria serta bobot untuk kriteria dilakukan berdasarkan kesepakatan antara peneliti dengan PT. Hini Daiki, Kriteria serta bobot kriteria dapat dilihat pada tabel 1 sebagai berikut :

Tabel 1. Bobot Kriteria

\begin{tabular}{cccc}
\hline Kriteria & Keterangan & Bobot & Jenis \\
\hline $\mathrm{C}_{1}$ & Keaktifan dalam & 0,10 & Benefit \\
& bekerja & & \\
$\mathrm{C}_{2}$ & Menguasai & 0,20 & Benefit \\
& pekerjaan & & \\
$\mathrm{C}_{3}$ & Disiplin & 0,15 & Benefit \\
$\mathrm{C}_{4}$ & Pengetahuan & 0,10 & Benefit \\
$\mathrm{C}_{5}$ & Kerja sama tim & 0,10 & Benefit \\
$\mathrm{C}_{6}$ & Kepribadian & 0,05 & Benefit \\
$\mathrm{C}_{7}$ & Penguasaan & 0,20 & Benefit \\
$\mathrm{C}_{8}$ & Bahasa & 0,10 & Benefit \\
\hline
\end{tabular}

Skala pembobotan untuk masing-masing kriteria dapat dilihat pada tabel 2 berikut:

Tabel 2 Skala Pembobotan

\begin{tabular}{cc}
\hline Keterangan & Bobot \\
\hline Sangat Baik & 5 \\
Cukup Baik & 3 \\
Baik & 2
\end{tabular}




\begin{tabular}{cc}
\hline Keterangan & Bobot \\
\hline Cukup & 1 \\
Buruk & 0 \\
\hline
\end{tabular}

Setelah kriteria dan skala bobot diketahui, selanjutnya menentukan alternatif serta nilai alternatif pada setiap kriteria, dapat dilihat pada tabel 3 berikut :

Tabel 3 Rating Kecocokan Alternatif Dengan Kriteria

\begin{tabular}{ccccccccc}
\hline Alternatif & $\mathrm{C}_{1}$ & $\mathrm{C}_{2}$ & $\mathrm{C}_{3}$ & $\mathrm{C}_{4}$ & $\mathrm{C}_{5}$ & $\mathrm{C}_{6}$ & $\mathrm{C}_{7}$ & $\mathrm{C}_{8}$ \\
\hline $\mathrm{A}_{1}$ & 2 & 5 & 1 & 5 & 1 & 2 & 1 & 3 \\
$\mathrm{~A}_{2}$ & 3 & 5 & 3 & 5 & 2 & 1 & 1 & 5 \\
$\mathrm{~A}_{3}$ & 1 & 3 & 2 & 3 & 2 & 0 & 2 & 5 \\
$\mathrm{~A}_{4}$ & 5 & 1 & 2 & 5 & 3 & 1 & 2 & 1 \\
$\mathrm{~A}_{5}$ & 5 & 5 & 3 & 1 & 1 & 1 & 3 & 3
\end{tabular}

\subsection{Membuat matriks keputusan}

Selanjutnya mengubah tabel rating kecocokan alternatif menjadi matriks keputusan menggunakan rumus (1), matriks keputusan dapat dilihat sebagai berikut:

$$
X=\left[\begin{array}{llllllll}
2 & 5 & 1 & 5 & 1 & 2 & 1 & 3 \\
3 & 5 & 3 & 5 & 2 & 1 & 1 & 5 \\
1 & 3 & 2 & 3 & 2 & 0 & 2 & 5 \\
5 & 1 & 2 & 5 & 3 & 1 & 2 & 1 \\
5 & 5 & 3 & 1 & 1 & 1 & 3 & 3
\end{array}\right]
$$

\subsection{Matriks Normalisasi}

Selanjutnya sesuai dengan rumusn (2) adalah menghitung matriks normalisasi. Hasilnya yaitu :

$$
\begin{aligned}
X_{1,1}= & \frac{2}{\sqrt{2^{2}+3^{2}+1^{2}+5^{2}+5^{2}}}=\frac{2}{8}=0.25 \\
& \cdots \\
& \cdots \\
& \cdots \\
X_{8,5}= & \frac{3}{\sqrt{3^{2}+5^{2}+5^{2}+1^{2}+5^{2}}}=\frac{3}{8,306}=0,361
\end{aligned}
$$

Hasil perhitungan dari Normalisasi Matriks, maka diperoleh matriks Nilai Normalisasi $\left(\mathrm{X}_{\mathrm{ij}}\right)$ sebagai berikut:

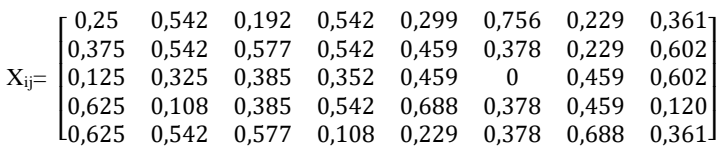

\subsection{Menghitung nilai optimasi}

Perhitungan Nilai Optimasi Multiobjektif MOORA (max-min) dalam kasus ini mengacu pada persamaan pada rumus.....(3). Contoh perhitunganya sebagai berikut :

$$
\begin{aligned}
& X_{11}=0,25 \times 0,10=0,025 \\
& X_{21}=0,542 \times 0,20=0,108 \\
& \cdots \\
& \ldots \\
& X_{85}=0,361 \times 0,10=0,036
\end{aligned}
$$

Setelah hasil normalisasi di kalikan dengan bobot setiap kriteria menghasilkan nilai pada di bawah ini :

$$
X w j=\left[\begin{array}{cccccccc}
0,025 & 0,108 & 0,029 & 0,054 & 0,023 & 0,038 & 0,046 & 0,036 \\
0,038 & 0,108 & 0,087 & 0,054 & 0,046 & 0,019 & 0,046 & 0,006 \\
0,013 & 0,065 & 0,058 & 0,033 & 0,046 & 0 & 0,092 & 0,006 \\
0,063 & 0,022 & 0,058 & 0,054 & 0,069 & 0,019 & 0,092 & 0,012 \\
0,063 & 0,108 & 0,087 & 0,011 & 0,023 & 0,019 & 0,138 & 0,036
\end{array}\right]
$$

Hasil perkalian dari penyetaraan bobot selanjutnya untuk perhitungan optimasi dimana ada nilai maksimal (atribut keuntungan/benefit) dan minimal(atribut yang tidak menguntukan). Pada kasus ini hanya terdapat nilai benefit/maksimal jadi setiap kriteria akan ditambahkan pada masing-masing alternatif untuk mendapatkan hasilnya :

$\mathrm{A} 1=0,025+0,108+0,029+0,054+0,023$ $+0,038+0,046+0,036=0,3593$

$\mathrm{A} 2=0,038+0,108+0,087+0,054+0,046$ $+0,019+0,046+0,06=0,4577$

$\mathrm{A} 3=0,013+0,065+0,058+0,033+0,046$ $+0+0,092+0,06=0,3657$

$\mathrm{A} 4=0,063+0,022+0,058+0,054+0,069$ $+0,019+0,092+0,012=0,3877$

$\mathrm{A} 5=0,063+0,108+0,087+0,011+0,023$ $+0,019+0,138+0,036=0,484$

\subsection{Perangkingan}

Langkah terakhir yaitu perangkingan. Berikut ini didapatkan hasil dari sistem penunjang keputusan pemilihan karyawan magang dapat dilihat pada tabel 4 berikut:

Tabel 4 Hasil Perangkingan

\begin{tabular}{ccc}
\hline Alternatif & Hasil & Rangking \\
\hline $\mathrm{A}_{5}$ & 0,484 & 1 \\
$\mathrm{~A}_{2}$ & 0,4577 & 2 \\
\hline
\end{tabular}




\begin{tabular}{ccc}
\hline \multicolumn{3}{c}{ METIK VOLUME. 5 NOMOR. 12021} \\
\hline Alternatif & Hasil & Rangking \\
\hline $\mathrm{A}_{4}$ & 0,3877 & 3 \\
$\mathrm{~A}_{3}$ & 0,3657 & 4 \\
$\mathrm{~A}_{1}$ & 0,3593 & 5 \\
\hline
\end{tabular}

Sehingga dari hasil perhitungan diatas menghasilkan rating untuk calon karyawan yang terpilih untuk magang ke Luar Negeri dimana nilainya yang paling tinggi adalah yang layak berangkat ke Luar Negeri, kemudian dapat disimpulkan bahwa karyawan yang berhak pergi ke Luar Negeri adalah Alternatif 5 dengan hasil 0,484.

\section{Kesimpulan}

Berdasarkan hasil analisis dan perhitungan dengan metode MOORA, maka dapat ditarik beberapa kesimpulan yaitu :

1. Dengan adanya sistem pendukung keputusan, maka proses pemilihan karyawan magang menjadi akurat dan hasilnya tepat sasaran.

2. Metode Multi-Objective Optimization on the basis of Ratio Analysis (MOORA) dapat di terapkan padas sitem penunjang keputusan pemilihan karyawan magang.

\section{Saran}

Adapun saran yang terkait sistem pendukung keputusan pemilihan karyawan magang yang penulis lakukan yaitu perlu menambahkan beberapa kriteria lain yang relevan agar keputusan yang dihasilkan menjadi lebih optimal.

\section{Daftar Pustaka}

[1] Andy Rahman, "Sistem Pendukung Keputusan Seleksi Sumber Daya Manusia Di Perusahaan," Pros. Semin. Nas. Teknoin 2008, no. Mcdm, pp. 21-26, 2008.

[2] A. Putra and A. Prasetya, "ANALISIS EFEKTIVITAS PELATIHAN KARYAWAN KE LUAR NEGERI (Studi pada PT. Jakarta International
Container Terminal)," J. Adm. Bisnis

S1 Univ. Brawijaya, vol. 47, no. 1, pp. 39-46, 2017.

[3] Isa Rosita, Gunawan, and Desi Apriani, "Penerapan Metode Moora Pada Sistem Pendukung Keputusan Pemilihan Media Promosi Sekolah (Studi Kasus: SMK Airlangga Balikpapan)," Metik J., vol. 4, no. 2, pp. 55-61, 2020.

[4] E. Ismanto and N. Effendi, "Sistem Pendukung Keputusan Penerimaan Karyawan Dengan Metode Simple Additive Weighting (SAW)," SATIN Sains dan Teknol. Inf., vol. 3, no. 1, p. 1, 2017.

[5] A. Muhardono and R. Isnanto, "Penerapan Metode AHP dan Fuzzy

Topsis Untuk Sistem Pendukung Keputusan Promosi Jabatan," J. Sist. Inf. Bisnis, vol. 4, no. 2, pp. 108-115, 2014.

[6] A. Ariani, L. A. Abdillah, and F. Syakti, "Sistem Pendukung Keputusan Kelayanan TKI ke Luar Negeri Menggunakan FMADM," Sisfo, vol. 4, no. 5, pp. 336-343, 2013.

[7] A. Muharsyah, S. R. Hayati, M. I. Setiawan, H. Nurdiyanto, and Yuhandri, "Sistem Pendukung Keputusan Multi Obective Optimization On the Basis Of Ratio Analysis (MOORA)," JURIKOM (Jurnal Ris. Komputer), vol. 5, no. 2, pp. 19-23, 2018.

[8] K. N. A. Nur, S. R. Andani, and P. Poningsih, "Sistem Pendukung Keputusan Pemilihan Operator Seluler Menggunakan Metode MultiObjective Optimization on the Basis of Ratio Analysis (Moora)," KOMIK (Konferensi Nas. Teknol. Inf. dan Komputer), vol. 2, no. 1, pp. 61-65, 2018. 